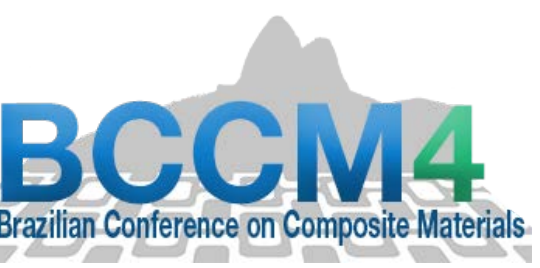

\title{
NEW METHOD TO OBTAIN A NATURAL AND VERSATILE “CELLULOSE/SILICA HYBRID COMPOSITES” FROM RICE HUSK WASTE AND YOUR APPLICATION FOR ABSORPTIVE PROCESSES
}

\author{
Marcelo P. da Rosa (1), Paulo H. Beck ${ }^{(1)}$, Felipe Kessler (1), Maria C. S. Bulhosa ${ }^{(1)}$, Paulo \\ M. T. Junior ${ }^{(1)}$
}

(1) School of Chemistry and Foods (EQA), Universidade Federal do Rio Grande, Brazil

https://doi.org/10.21452/bccm4.2018.10.12

\begin{abstract}
The synthetic hybrid composites formed by organics and inorganics molecules have potential to become important materials for many applications. The present study has objective to extract a "cellulose/silica" compound natural, directly from rice husk waste whose original structure is formed by lignin, cellulose, hemicellulose and silica. The obtaining of adsorbent (cellulose/silica composite) from rice husk was carried first by modified Organosolv method and the second step involved an agressive oxidative bleaching process. The samples were characterized by ash test, FTIR, SEM, XRD and BET. Tests was performed to verify the potential of the composite extracted as an adsorbent for dyes and metals in aqueous solutions and mycotoxins in barley. The results show the oxidative bleaching can be modified (increasing the cycles) to obtain different composites with different amounts of silica/cellulose. Besides that was possible to observe the "cellulose/silica hybrid composite" material have good capacity to remove different kinds of compounds in different matrix (liquid or solid phase). All adsorption tests performed presented maximum adsortions for the metals of until 92\%; in other hand, the cellulose/silica composite removed $82 \%$ of crystal violet dye while the recoveries of mycotoxins show values between $64 \%$ and $74 \%$. These results show great versatility for this hybrid material extracted from rice husk.
\end{abstract}

\section{INTRODUCTION}

Rice Husk (RH) is an abundant waste from agroindustry in south of Brazil, however most of this waste does not receive the proper destination. The main characteristic of $\mathrm{RH}$ is your resilience and resistance to chemical and biological attack. Besides $\mathrm{RH}$ is rich in natural compounds like cellulose, lignin and silica [1]. Cellulose shows interesting possibility to produce hybrid materials with inorganic compounds like the titanium and zinc oxides and silica, for instance [2]. The possibility of combining the properties of organic and inorganic compounds is very important and the researches have increased recently. Silica, for instance, can be incorporated into a wide variety of biopolymers such as cellulose, starch and chitin [3]. 
This combination of materials can result in the possibility of promising applications for these composites like protective coatings, catalysis system, sensors and biological applications.

In the same way, the methodologies to produce hybrid (organic-inorganic) materials can be difficult and expansive, because involves many steps to make the linkage between two different materials. The nature have used frequently combinations of these compounds to form materials with better properties. Therefore, the extraction of a structure composed by part organic (cellulose) and inorganic (silica) to form a "cellulose/silica hybrid composite" with adsorbent properties can be important because two reasons, first; the recuperation of an abundant waste and second; the getting of a versatile and low cost adsorbent.

The process of adsorption is an important tool to remove contaminants or compounds presents in low concentration in aqueous solution mainly. In this way has become important the development of adsorbents "eco-friendly" and versatile to act in situations that go since water treatment until the quantitative analysis of contaminants in industrial products. This work was divided in two parts: the first is the extraction of a natural "cellulose/silica hybrid composite" from rice husk and your characterization, this step generated materials with different amount of silica and cellulose in your composition. The second part involves the application this composite obtained in the removal of copper, silver and Cristal Violet dye from an aqueous matrix. Your versatility and capacity of adsorption also has been tested against a solid matrix of barley in the recovery of three kinds of mycotoxins.

\section{EXPERIMENTAL PROCEDURE}

Firstly, to obtain the natural "cellulose/silica hybrid composite” adsorbent from Rice Husk (RH) was necessary make a delignification process, for this porpouse was carried the Organosolv process modified by Rosa et al. (2017) [4]. This process use Ethanol and Sulfuric acid under reflux conditions to remove most parte of Lignin from RH. After delignification process, the solid resulting presented in your structure cellulose, hemicellulose and silica with low amount of lignin. Than the RH was put in a flask with $100 \mathrm{ml}$ with sodium hypochlorite (6\% active chlorine) under acid $\mathrm{pH}$ and heating for 2 hours to remove residual lignin and hemicellulose by oxidative bleaching. The oxidative bleaching can be stopped when the Kappa Number be less than 5,0 (analysis to check the residual lignin at samples). After the oxidative bleaching the compounds obtained is dried and forwarded to characterization and tests of adsorptions.

Ashes test (ASTM D1102) was used to determine the silica amount. FTIR- Fourier Transform Infrared Spectroscopy (Shimadzu - IR PRESTIGE-21) determined the chemical structure. The investigation of surface morphology was made by scanning electron microscopy (SEM - Jeol JSM 6060). The same equipment carried the EDS. The surface areas was measured by $\mathrm{N} 2$ adsorption-desorption at $77 \mathrm{~K}$ at Brunauer-Emmett-Teller (BET) method using a Quanta Chrome NOVA. A powder X-ray diffraction (XRD) method was used to determine the crystallinity by using a Rigaku - Miniflex 300 (Japan), this analysis was carried out with the generator settings of current of $30 \mathrm{~mA}$ and tension of $40 \mathrm{kV}$ with $\mathrm{Cu}$ as an anode material at a temperature of $25^{\circ} \mathrm{C}$ with a step size (2h) of 0.033 . An X-ray tube produced a monochromatic CuKa radiation of wavelength $0.154 \mathrm{~nm}$, recorded between $10^{\circ}$ and $80^{\circ}$.

The cellulose/silica composite obtained were tested like adsorbent for cationic dye (Crystal Violet) and two metals $\left(\mathrm{Ag}^{+1}\right.$ and $\left.\mathrm{Cu}^{+2}\right)$ to check the capacity and the best conditions to remove this compounds in aqueous solution. All assays were performed in batch mode, using a thermostated agitator (Marconi, MA 093, Brazil) at $220 \mathrm{rpm}$ with volume of solution of $50 \mathrm{~mL}$. In other hand the recovery of three mycotoxins (group of Trichothecene: nivalenol- NIV; deoxynivalenol - DON; 3-acetyl- deoxynivalenol + 15-acetyl- deoxynivalenol - ADONS) was performed by matrix solid-phase dispersion (MSPD), but in this time the matrix was barley 
(solid matrix) and not water. The final recoveries was measured by Liquid chromatographymass spectrometry.

\section{RESULTS AND DISCUSSION}

\subsection{Characterization}

The ashes test revealed if the number of cycles oxidative bleaching are increased, even after to remove residual lignin, that's results in a bigger degradation of cellulose and increase of silica amount. The exposure of composite to more than one cycles of bleaching resulted in two samples whose the amount of silica was increased from $30.01 \%$ to $42.26 \%$. The FTIR spectrum (Figure 1) does not shows the lignin characteristic bands any more, but the stretch bands Si-OSi $\left(1080 \mathrm{~cm}^{-1}\right)$ and Si-H $\left(469 \mathrm{~cm}^{-1}\right)$ are present. The O-H $\left(3300 \mathrm{~cm}^{-1}\right)$, C-O-C and C-O (900$1200 \mathrm{~cm}^{-1}$ ) stretch bands of the cellulose are observed for two samples. Another important characteristic about this spectrum is the similarity of the curves. This mean the reduction of cellulose amount at the samples do not result in significant chemistry change in the cellulose/silica hybrid composites extracted.

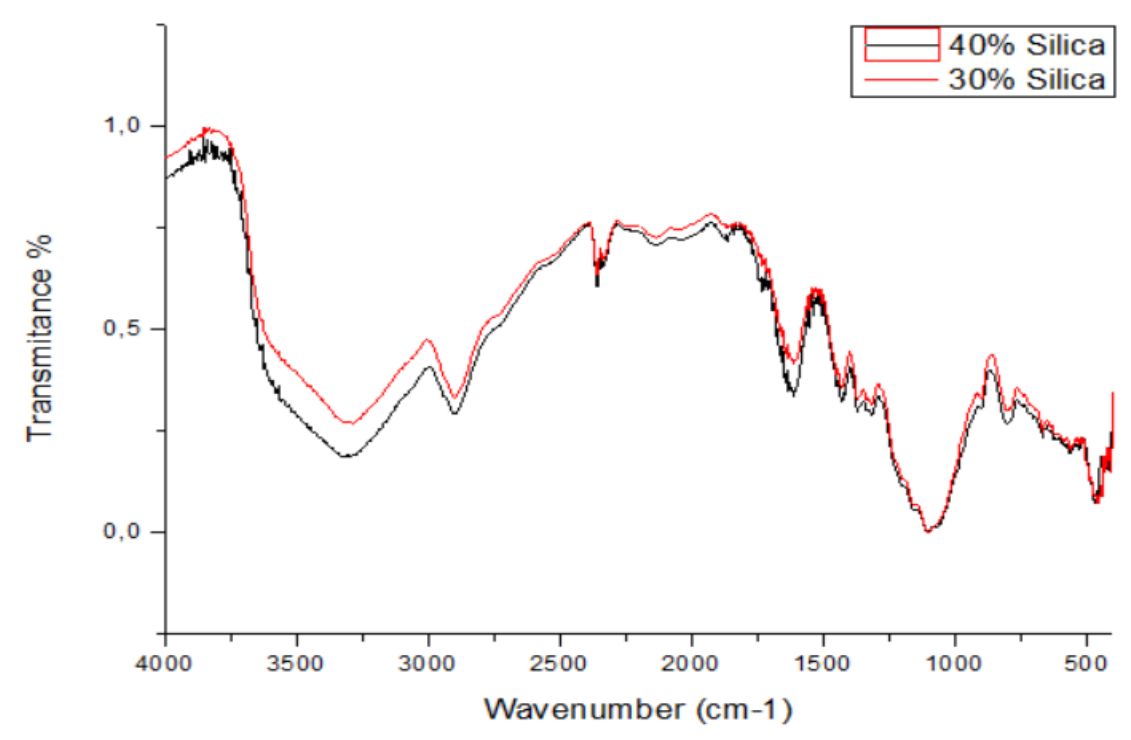

Figure 1: Spectrum of FTIR for two samples obtained the red line with $30 \%$ of silica and black line $40 \%$ of silica.

The Figure 2 (below) show that the more aggressive oxidative bleaching (more cycles) results beyond of decrease of cellulose amount by degradation in each sample, but also in reduction of particles size. In the future can be interesting try the obtantion of nanostructures by these methods.

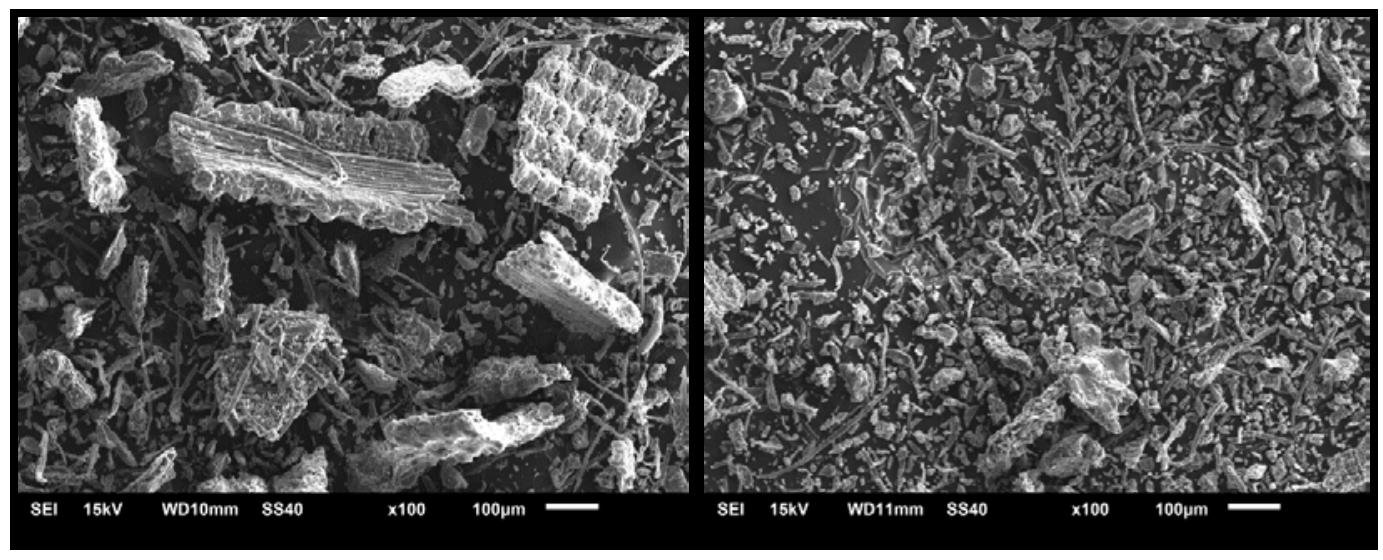


Figure 2: Image at left is sample with $30 \%$ silica, while the image at right is magnification of samples with $40 \%$ of silica.

The Figure 2 (left side less times bleaching cycles $\mathrm{x}$ right side more times bleaching cycles) show the difference of the morphological structures (reduction of particles size, mainly) between two samples of "cellulose/silica composite" adsorbent. The EDS analysis (Figure not shown), it was found that the "cellulose/silica composite" adsorbent surface is composed mainly by $\mathrm{C}, \mathrm{O}$ and $\mathrm{Si}$. Besides it is possible point some important characteristics. The EDS analysis (Figure not shown), it was found that the "cellulose/silica composite" adsorbent surface is composed mainly by $\mathrm{C}, \mathrm{O}$ and $\mathrm{Si}$. Besides it is possible point some important characteristics. The two composites analysed, with $30 \%$ and $40 \%$ of silica, showed heterogeneous surfaces on your composition. The most porous surfaces showed more amount of carbon and oxygen, while the smooth surfaces presented more quantity of silica than other elements.

The Rice Husk structure consists primarily of lignin, hemicellulose, cellulose and silica. The lignin and hemicellulose macromolecules are amorphous, but the cellulose, molecules are semicrystalline. Furthermore the literature describe the silica present in rice husk like an amorphous silica distributed on their cell walls, forming silica-cuticle and silica-cellulose double layers on the surface of husks.
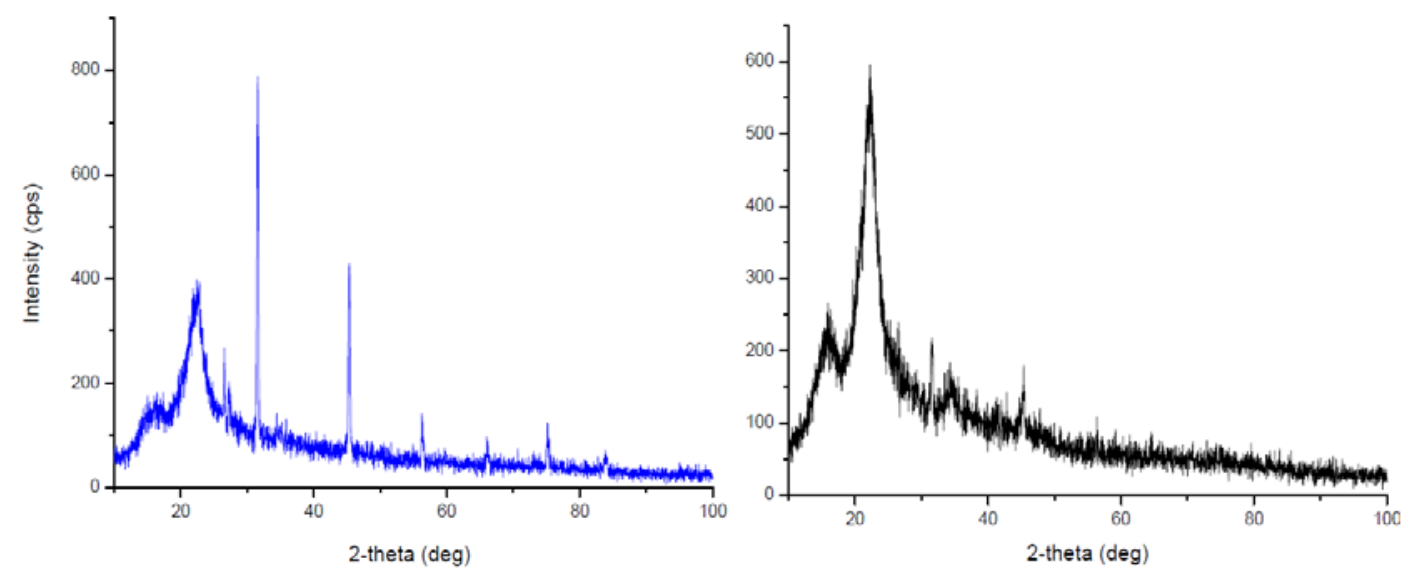

Figure 3: XRD plot of cellulose samples first (left) with more amount of silica (40\%) and second (right) with less silica (30\%).

The X-ray diffraction pattern of composite after oxidative bleaching is shown in Figure 3 for the two different amount of silica. The right side contains $30 \%$ of silica while left side is the sample with $40 \%$ of silica. The right side it shows two well-defined diffraction peaks at 2 theta $=15.9^{\circ}$ and 2 theta $=22.5^{\circ}$, there are observed in cellulose natural fibers. These two peaks are attributed to the typical crystallographic plane of cellulose, which exhibits a monoclinic structure [5]. The spectrum at left side, show the reduction of cellulose peaks if compare the two XRD pattern, this was expected because the cellulose is attacked during the bleaching and your amount decrease. However the samples of "cellulose/silica composite" material that present more amount of silica (at left) revealed others important peaks ( 2 theta $=31,5 ; 45,3$; 56,2 and 75.1). Although information about the silica structure in rice husk talked about kinds amorphous of silica, the peaks that appear at XRD open the possibility for existence of some structures of cristobalite in the samples after bleaching [6]. This structures are commonly observed in XRD patterns of rice husk ashes and depend of the conditions of burn to be able observed.

The surface area determined by BET method show values in the order of 18,422 $\mathrm{m} 2 / \mathrm{g}$ (30\% silica) and 9,534 $\mathrm{m} 2 / \mathrm{g}$ (40\% silica). That's values for surface area can be consider small if are compared with some kinds of active carbon, but this surface area is more than 10 times bigger 
than common cellulose powder and the same for cellulose nanocrystals obtained in other works [7]. The decrease of surface area on samples with $30 \%$ silica against the samples with $40 \%$ of silica opposes the result observed in SEM images where the size of particles reduce when de amount of silica increase. This result can be explained because the pores of silica particles in this case are filled by organic molecules resulting in a smaller surface area [8]. The removal of these structures from the pores in the silica particles can contributed very much to change these results. For now, probably the cellulosic amount of composite present bigger influence to increase or reduce the surface area.

\subsection{Results of application tests}

Table 1 shows the adsorption results for removal of $\mathrm{Ag}^{+1}, \mathrm{Cu}^{+2}$ and Crystal Violet Dye in aqueous solution with adsorption times less than 30 minutes.

Table 1: Percentage of removal with two different composites of cellulose/silica.

\begin{tabular}{cccc}
\hline & $\mathrm{pH}$ & $30 \%$ Silica & $40 \%$ Silica \\
\hline Dye (Violet Crystal) & 8,0 & $82,42 \%$ & $79,49 \%$ \\
$\mathrm{Ag}^{+}$ & 6,5 & $75,26 \%$ & $92,01 \%$ \\
$\mathrm{Cu}^{+2}$ & 6,5 & $51,10 \%$ & $72,36 \%$ \\
\hline
\end{tabular}

These results present at Table 1 show that adsorbent can remove from aqueous solutions two different kinds of contaminants, metals e dyes. In other hand is possible to evaluate that the amount of silica and cellulose have great importance for the each kinds of substance (organic or inorganic) can be adsorbed. The copper and silver show better removal by the samples with more silica amount while the dye is adsorbed better in sample with more amount of cellulose.

The cellulose usually do not present god results for adsorption due your cristalinity. To compare with other results, in others works which used cellulose, modified cellulose and even chitosan, the results for silver adsorption showed maximum $64 \%$ of removing [9] while copper do not presented results bigger than 50\% of adsorption [10]. On the other hand for the Violet Crystal presented the best result around $70 \%$ of removal using pure cellulose [10]. However, the most important question about the "natural cellulose/silica composite", besides of your low cost, is your capacity of removal different kinds of substances (metal, dyes and mycotoxins). The others works use cellulose only for one purpose, metal or dyes.

Until now, the application of the composite cellulose/silica was to "purify" water samples. Now the next application involves the quantitative analysis of some contaminants (not desirable) present in feedstock of industrial use. The Table 2 show the results of recoveries for mycotoxins from the barley (here was used a solid matrix, not aqueous media). This time was used only the sample with $30 \%$ of silica and $70 \%$ of cellulose. The decision was made because the adsorbent with more amount of cellulose showed better results to remove organic compounds.

Table 2: values for recoveries of three kinds of mycotoxins by the composite with $30 \%$ of silica

\begin{tabular}{ccc}
\hline Mycotoxin & Recoveries & RSD: relative standard deviations \\
\hline NIV & $64 \%$ & $5,3 \%$ \\
DON & $78 \%$ & $3,5 \%$
\end{tabular}




$\begin{array}{lll}\text { ADONS } & 72 \% & 2,8 \%\end{array}$

The values considered acceptable by The Brazilian Health Regulatory Agency (ANVISA) is recoveries between 70 and $120 \%$ for trace compounds and a repeatability (RSD) lower than $20 \%$. The importance of these results are the possibility for the use of theses "cellulose/silica hybrid composites" in quantitative analysis to help the quality control of barley. Today for this procedure is used $\mathrm{C}_{18}$ (octadecy-silica), this material show recovery between 80 to $90 \%$ for these mycotoxins. But we need higlight wich the problem about $\mathrm{C}_{18}$ is the hight cost of this material.

\section{CONCLUSIONS}

- The new procedure performed at rice husk make possible obtaining a natural composite formed by silica and cellulose (“cellulose/silica hybrid composites”), without lignin and hemicellulose.

- The process of bleaching show important to control the amount of silica in the samples by the increase of the cycles of oxidation.

- The material obtained from rice husk presented low cost and good properties to remove (by adsorption) different kinds of contaminants in aqueous solution or solid phase.

- The next step is the standard study of adsorption for all compounds removed to understand better this process proceed changes in chemical and physical structure of this composite.

\section{ACKNOWLEDGEMENTS}

To FURG, PPGQTA, LAMCA (FURG) and LAPAM (UFSM).

\section{REFERENCES}

[1] Laufenberg, G., Kunz, B. and Nystroem, M., "Transformation of vegetable waste into value added products”, Bioresour. Technol. 87(2) (2003) 167-198.

[2] Bobowska, I., Wojciechowski, P. and Halamus, T., "Organic-inorganic nanocomposites of (2-hydroxypropyl) cellulose as a precursor of nanocrystalline zinc oxide layers", Polymer. Adv. Tech. 19(12) (2008) 1860-1867.

[3] He, X., Du, M., Li, H. and Zhou T., "Removal of direct dyes from aqueous solution by oxidized starch cross-linked chitosan/silica hybrid membrane”, Int. J. Biol. Macromolec. 82 (2016) 174181.

[4] Rosa, M.P., Beck, P.H., Müller, D.G., Moreira, J.B., Silva, J.S. and Durigon, A.M.M., "Extraction of Organosolv Lignin from Rice Husk under Reflux Conditions”, Biolog. and Chem. Res. 4(4) (2017) 87 - 98.

[5] Indran, S., R. Edwin Raj, and V. S. Sreenivasan. "Characterization of new natural cellulosic fiber from Cissus quadrangularis root." Carbohy. Poly. 110 (2014): 423-429.

[6] Yalcin, N., and V. Sevinc. "Studies on silica obtained from rice husk." Ceramic. Inter. 27.2 (2001): 219-224.

[7] Lu, P. and Hsieh, Y.-L., "Preparation and properties of cellulose nanocrystals: rods, spheres, and network”, Carbohydr Polym. 82(2) (2010) 329-336.

[8] Hu, S. and Hsieh, Y.-L., "Preparation of activated carbon and silica particles from rice straw", ACS Sustain. Chem. 2(4) (2014) 726-734.

[9] Liu, P., Sehaqui, H., Tingaut, P., Wichser, A., Oksman, K. and Mathew, A. P., "Cellulose and chitin nanomaterials for capturing silver ions $(\mathrm{Ag}+)$ from water via surface adsorption”, Cellul., 21(1) (2014) 449-461. 
$4^{\text {th }}$ Brazilian Conference on Composite Materials. Rio de Janeiro, July $22^{\text {nd }}-25^{\text {th }}, 2018$

[10] Li, N. and Renbi B., "Copper adsorption on chitosan-cellulose hydrogel beads: behaviors and mechanisms", Sep. and purify. Techn., 42.3 (2005) 237-247.

[11] Zhou, Y., Zhang, M., Wang, X., Huang, Q., Min, Y., Ma, T., and Niu, J., "Removal of crystal violet by a novel cellulose-based adsorbent: comparison with native cellulose", Ind. \& Eng. Chem. Res., 53(13) (2014) 5498-5506. 